\title{
Application of artificial intelligence in load frequency control of interconnected power system
}

\author{
Surya Prakash ${ }^{1}$, S. K. Sinha ${ }^{2}$ \\ ${ }^{1}$ Department of Electrical \& Electronics Engineering, Shepherd School of Engineering \& Technology, Sam Higginbottom Institute of Agriculture, Technology \& \\ Sciences- Deemed University, Allahabad, INDIA \\ ${ }^{2}$ Department of Electrical Engineering, Kamala Nehru Institute of Technology, Sultanpur-UP, INDIA, \\ ${ }^{1}$ Corresponding Author Emaisl- sprakashgiri0571@yahoo.com Phone: 09956722055
}

\begin{abstract}
This paper presents the use of artificial intelligence to study the load frequency control of interconnected power system. In the proposed scheme, a control methodology is developed using Artificial Neural Network (ANN) and Fuzzy Logic controller (FLC) for interconnected hydro-thermal power system. The control strategies guarantees that the steady state error of frequencies and inadvertent interchange of tie-lines power are maintained in a given tolerance limitations. The performances of the controllers are simulated using MATLAB/SIMULINK package. A comparison of Fuzzy controller and ANN controller based approaches shows the superiority of proposed ANN based approach over Fuzzy one for different loading conditions ( $1 \%$ and $2 \%$ step load variations). The simulation results also tabulated as a comparative performance in view of settling time and peak over shoot.
\end{abstract}

Keywords: Load Frequency Control(LFC), Fuzzy Logic Controller, ANN Controller, Area Control error(ACE), Tie-line, MATLAB / SIMULINK.

\section{Introduction}

Automatic Generation Control (AGC) or Load Frequency Control is a very important issue in power system operation and control for supplying sufficient and reliable electric power with good quality. An interconnected power system can be considered as being divided into control area, all generators are assumed to form a coherent group (George et al, 2001). Load Frequency Control (LFC) is being used for several years as part of the Automatic Generation Control (AGC) scheme in electric power systems. One of the objectives of AGC is to maintain the system frequency at nominal value $(50 \mathrm{hz})$. In the steady state operation of power system, the load demand is increased or decreased in the form of Kinetic Energy stored in generator prime mover set, which results the variation of speed and frequency accordingly. Therefore, the control of load frequency is essential to have safe operation of the power system (Kothari et al. 2003; Kundur, 1994; Wadhawa, 2007).

Automatic generation control (AGC) is defined as, the regulation of power output of controllable generators within a prescribed area in response to change in system frequency, tie-line loading, or a relation of these to each other, so as to maintain the schedules system frequency and / or the established interchange with other areas within predetermined limits (Elgerd, 1971). Therefore, a control strategy is needed that not only maintains constancy of frequency and desired tie-power flow but also achieves zero steady state error and inadvertent interchange. Among the various types of load frequency controllers, the most widely employed is the conventional proportional integral (PI) controller. The PI controller is very simple for implementation and gives better dynamic response, but their performances deteriorate when the complexity in the system increases due to disturbances like load variation boiler dynamics (Talaq et al. 1999; Arvindan et al. 2009). Therefore, there is need of a controller which can overcome this problem. The Artificial Intelligent controller like Fuzzy and Neural control approach is more suitable in this respect. Fuzzy system has been applied to the load frequency control problems with rather promising results (Nanda et al, 2003). The salient feature of these techniques is that they provide a model- free description of control systems and do not require model identification. The fuzzy controller offers better performance over the conventional controllers, especially, in complex and nonlinearities associated 
system. In (Mangla et al. 2004) Fuzzy control was applied to the two region interconnected reheat thermal and hydro power system. However, it is demonstrated good dynamics only when selecting the specific number of membership function, so that the method had limitation. To over come this Artificial Neural Network (ANN) controller, which is an advance adaptive control configuration, is used because the controller provides faster control than the others (Demiroren et al. 2001).

In this paper, the performance evaluation based on Fuzzy controller and Artificial Neural controller for two areas interconnected hydro-thermal power plant is proposed. To enhance the performance of fuzzy and neural controller sliding surface is included. The sliding concept arises due to variable structure concept (VSC). The objective of VSC has been greatly extended from stabilization to other control functions. The most distinguished feature of VSC is its ability to result in very robust control systems; in many cases invariant control system result. The term 'invariant' means that the system is completely insensitive to parametric uncertainty and external disturbances (John et al; 1993, Kumar et al. 1985).

\section{The Investigated Power System}

The detailed block diagram modeling of two area thermal-hydro power system for load frequency control investigated is shown in figure 1. An extended power system can be divided into a number of load frequency control areas interconnected by means of tie lines. Without loss of generality one can consider a two- area case connected by single tie line (Surya-Prakash et al.2009).

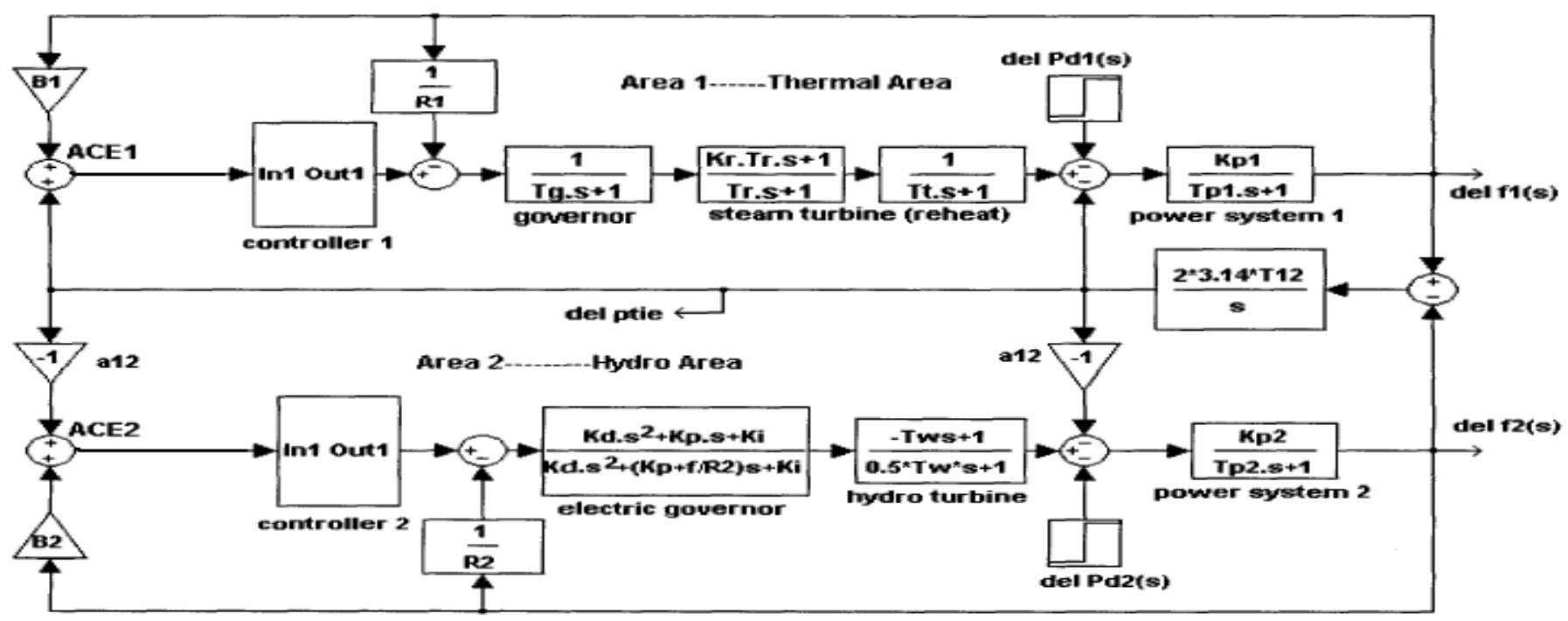

Fig. 1 : Block diagram model of hydro-thermal reheat power system.

The control objectives are as follows:

- $\quad$ Each control area as for as possible should supply its own load demand and power transfer through tie line should be on mutual agreement.

- Both control areas should controllable to the frequency control.

In an isolated control area case the incremental power $\left(\Delta P_{G}-\Delta P_{D}\right)$ was accounted for by the rate of increase of stored kinetic energy and increase in area load caused by increase in frequency. Since a tie line transports power in or out of an area, this fact must be accounted for in the incremental power balance equation of each area.

2.1 Modeling of the tie-line : The power transfer equation through tie line is given by,

$$
P_{12}=\frac{\left|V_{1}\right|\left|V_{2}\right|}{x} \sin \left(\delta_{1}-\delta_{2}\right)
$$

considering area 1 has surplus power and transfers to area 2

$\mathrm{P}_{12}=$ Power transferred from area 1 to 2 through tie line.

$P_{12}=\frac{\left|\mathrm{V}_{1}\right| \cdot\left|\mathrm{V}_{2}\right|}{\mathrm{X}_{12}} \cdot \operatorname{Sin}(\delta 1-\delta 2)$

Where

$\delta_{1}$ and $\delta_{2}=$ Power angles of end voltages $\mathrm{V}_{1}$ and $\mathrm{V}_{2}$

of equivalent machine of the two areas respectively.

$\mathrm{X}_{12}=$ reactance of tie line. 
The order of the subscripts indicates that the tie line power is define positive in direction 1 to 2 .

For small deviation in the angles and the tie line power changes with the amount i.e. small deviation in $\delta_{1}$ and $\delta_{2}$ changes by $\Delta \delta 1$ and $\Delta \delta 2$,

Power $\mathrm{P}_{12}$ changes to $\mathrm{P}_{12}+\Delta P_{12}$

Therefore,

Power transferred from Area 1 to Area 2 is given by the following equation

$$
\begin{aligned}
& \Delta P_{12}(s)=\frac{2 \pi T^{o}}{s}\left(\Delta f_{1}(s)-\Delta f_{2}(s)\right) \\
& \mathrm{T}^{0}=\text { Torque produced }
\end{aligned}
$$

The above equation can be represented as in Fig. 2

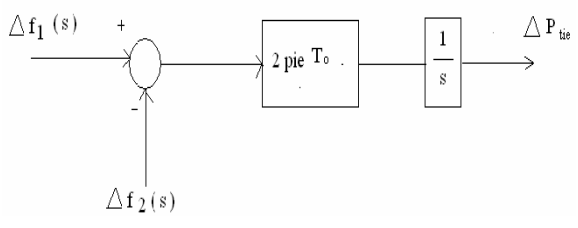

Fig. 2 : Block Diagram Representation of a Tie -Line

2.2 Tie line Control: In normal operation the power on the tie-line follows from the equation i.e.

$$
\begin{aligned}
& {\left[\Delta P_{T 1}(s)-\Delta P_{E 1}(s)-\Delta P_{12}(s)\right]=\frac{2 H_{1}}{f_{o}} s \Delta f_{1}(s)+B_{1} \Delta f_{1}(s)} \\
& =\frac{2 H_{1}}{f_{0}} \Delta f_{1}(s) B_{1}\left[\frac{1}{B_{1}} s+1\right] \\
& \text { If } \quad \frac{2 H_{1} B_{1}}{f_{o}}=\frac{1}{K_{P 1}} \\
& \frac{1}{B_{1}}=T_{P 1}
\end{aligned}
$$

Equation (4) can be written as

$$
\begin{gathered}
\Delta f_{1}(s)=G_{P 1}(s)\left[\Delta P_{T 1}(s)-\Delta P_{E 1}(s)-\Delta P_{12}(s)\right] \\
G_{P 1}(s)=\frac{K_{P_{1}}}{1+s T_{P 1}} \\
\Delta P_{12}=\Delta \mathrm{P}_{21}
\end{gathered}
$$

Where $\Delta P_{E} \quad$ is real load change

Due to the action of turbine controllers, the generator increases its output by the amount $\Delta P_{T}$.

The net surplus power $\Delta P_{T}-\Delta P_{E}$ will be absorbed by the system.

Tie-line bias control is used to eliminate steady state error in frequency in tie-line power flow. This states that the each control area must contribute their share to frequency control in addition for taking care of their own net interchange.

Let $\quad \mathrm{ACE}_{1}=$ area control error of area 1

$\mathrm{ACE}_{2}=$ Area control error of area 2

In these control areas, $\mathrm{ACE} 1$ and $\mathrm{ACE} 2$ are made linear combination of frequency and tie line power error.

$$
\begin{aligned}
& \mathrm{ACE}_{1}=\Delta P_{12}+\mathrm{b}_{1} \Delta f_{1} \\
& \mathrm{ACE}_{2}=\Delta P_{21}+\mathrm{b}_{2} \Delta f_{2}
\end{aligned}
$$


where the constant $\mathrm{b} 1 \& \mathrm{~b} 2$ are called area frequency bias of area 1 and area 2 respectively. Now $\triangle P R \quad 1$ and $\triangle P R \quad 2$ are mode integral of ACE1 and ACE2 respectively.

$$
\begin{aligned}
& \Delta P R 1=-\mathrm{Ki}_{1} \int_{0}^{\mathrm{t}}\left(\Delta \mathrm{P}_{12}+b_{1} \Delta f_{1}\right) d t \\
& \Delta P R 2=-\mathrm{Ki}_{2} \int_{0}^{\mathrm{t}}\left(\Delta \mathrm{P}_{21}+b_{2} \Delta f_{2}\right) d t
\end{aligned}
$$

Taking Laplace transform of the above equation, we get

$$
\begin{gathered}
\Delta P R_{1}(s)=-\frac{\mathrm{Ki}^{1}}{\mathrm{~s}}\left[\Delta P_{12}(s)+\mathrm{b}_{1} \Delta f_{1}(\mathrm{~s})\right] \\
\Delta P R_{2}(s)=-\frac{\mathrm{Ki}_{2}^{2}}{\mathrm{~s}}\left[\Delta P_{21}(s)+\mathrm{b}_{2} \Delta f_{2}(\mathrm{~s})\right]
\end{gathered}
$$

The step changes $\Delta P_{D 1}$ and $\Delta P_{D 2}$ are applied simultaneously in control area 1 and 2 respectively. When steady state conditions are reached, the output signals of all integrating blocks will be constant and their input signal must become zero.

$$
\begin{gathered}
\text { i.e. } \Delta P_{12}+\mathrm{b}_{1} \Delta \mathrm{f}_{1}=0 \text { (input of integrating block }-\frac{K i_{1}}{s} \text { ) } \\
\left.\Delta P_{21}+\mathrm{b}_{2} \Delta \mathrm{f}_{2}=0 \text { (Input of integrating block }-\frac{K i_{2}}{s}\right) \\
\Delta \mathrm{f}_{1-} \Delta \mathrm{f}_{2}=0 \text { (Input of integrating block }-\frac{2 T_{12}}{s} \text { ) } \\
\Delta P_{12}=\Delta P_{\text {tie, } 1} \text { and } \Delta P_{21}=\Delta P_{\text {tie, }, 2}
\end{gathered}
$$

Therefore $\frac{\Delta P_{\text {tie }, 1}}{\Delta P_{\text {tie }, 2}}=-\frac{\mathrm{T}_{12}}{\mathrm{~T}_{21}}=-\frac{1}{\mathrm{a}_{12}}=\mathrm{constant}$

Hence $\Delta P_{\text {tie }, 1}=\Delta P_{\text {tie }, 2}=0$

$\triangle P R_{1}=\Delta P R_{2}$,

And $\Delta f_{1}=\Delta f_{2}=0$

Thus, under steady condition change in the tie- line power and frequency of each area is zero. This has been achieved by integration of ACEs in the feedback loops of each area (Surya-Prakash et al. 2009). Control methodology used (FLC \& ANN) is mentioned in next preceding sections.

\section{Fuzzy Logic Control}

Fuzzy logic is a thinking process or problem-solving control methodology incorporated in control system engineering, to control systems when inputs are either imprecise or the mathematical models are not present at all. Fuzzy logic can process a reasonable number of inputs but the system complexity increases with the increase in the number of inputs and outputs, therefore distributed processors would probably be easier to implement. Fuzzification is process of making a crisp quantity into the fuzzy (Ross, 1985). They carry considerable uncertainty. If the form of uncertainty happens to arise because of imprecision, ambiguity, or vagueness, then the variable is probably fuzzy and can be represented by a membership function.

Defuzzification is the conversion of a fuzzy quantity to a crisp quantity, just as fuzzification is the conversion of a precise quantity to a fuzzy quantity. The out put of a fuzzy process can be the logical union of two or more fuzzy membership functions defined on the universe of discourse of the output variables. There are many methods of defuzzification, out of which smallest of maximum method is applied in making fuzzy inference system (Ross, 1985).

3.1. SOM (Smallest of Maximum) Method: This is also called first (or last of maximum) and this method uses the overall output or union of all individual output fuzzy sets $C_{k}$ to determine the smallest value of the domain with maximum $z$ membership degree in

$\mathrm{C}_{\mathrm{k}}$ (Ross, 1985). The equation for $Z$ are as follows:

$z^{*}=\inf _{z \in z}\left\{z \in z \mid \mu c_{k}(z)=\operatorname{hgt}\left(c_{k}\right)\right\}$ 
The Fuzzy logic control consists of three main stages, namely the fuzzification interface, the inference rules engine and the defuzzification interface (Ha, 1998). For Load Frequency Control the process operator is assumed to respond to respond to variables error $(e)$ and change of error $(c e)$.

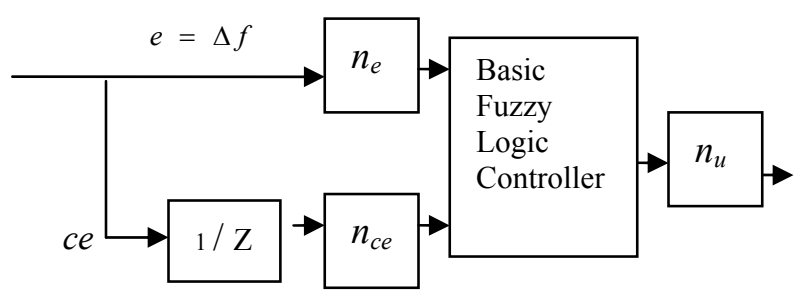

Fig. 3 Block diagram of a Fuzzy Logic controller

The variable error is equal to the real power system frequency deviation $(\Delta f)$. The frequency deviation $\Delta f$, is the difference between the nominal or scheduled power system frequency $\left(f_{\mathrm{N}}\right)$ and the real power system frequency $(f)$. Taking the scaling gains into account, the global function of the FLC output signal can be written as.

$$
\Delta P c=F\left[n_{c} \mathrm{e}(\mathrm{k}), \quad \mathrm{n}_{\text {ce }} \operatorname{ce}(\mathrm{k})\right]
$$

Where $n_{e}$ and $n_{c e}$ are the error and the change of error scaling gains, respectively, and $F$ is a fuzzy nonlinear function. FLC is dependant to its inputs scaling gains (Ha, 1998). The block diagram of FLC is shown in Fig $3, . n_{u}$ is output control gain (Talaq et al. 1999). A label set corresponding to linguistic variables of the input control signals, $e(k)$ and ce $(\mathrm{k})$, with a sampling time of 0.01 sec is as follows:

$$
\begin{aligned}
& \mathrm{L}(e, c e)=\{\mathrm{NB}, \mathrm{NM}, \mathrm{ZE}, \mathrm{PM}, \mathrm{PB}\}, \\
& \text { Where, } \mathrm{NB}=\text { Negative Big, } \\
& \mathrm{NM}=\text { Negative Medium, } \\
& \mathrm{ZE}=\text { Zero, } \\
& \mathrm{PM}=\text { Positive Medium, } \\
& \mathrm{PB}=\text { Positive Big }
\end{aligned}
$$

Fuzzy logic controller has been used in hydro-thermal interconnected areas. Attempt has been made to examine with five number of triangular membership function (MFs) which provides better dynamic response with the range on input (error in frequency deviation and change in frequency deviation) i.e universe of discourse is -0.25 to 0.25 . The numbers of rules are 25 .

The membership functions (MFs) for the input variables are shown in Fig.4.

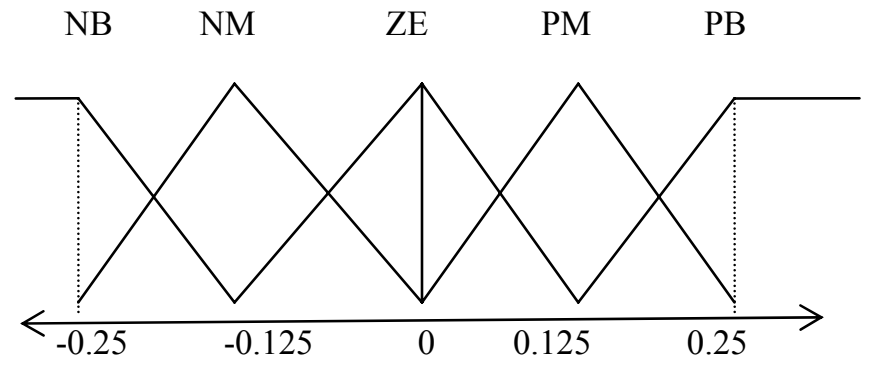

Table 1. Fuzzy inference rule for Fuzzy Logic Control

Fig.4 : Membership Function for the control input variables

\begin{tabular}{|c|c|c|c|c|c|c|}
\hline Input & \multicolumn{6}{|c|}{$e(k)$} \\
\hline \multirow{5}{*}{$c e(k)$} & & NB & NM & ZE & PM & PB \\
\cline { 2 - 7 } & NB & NB & NB & NM & NM & ZE \\
\cline { 2 - 7 } & NM & NB & NB & NM & ZE & ZE \\
\cline { 2 - 7 } & ZE & NM & NM & ZE & PM & PM \\
\cline { 2 - 7 } & PM & ZE & PM & PM & PB & PB \\
\cline { 2 - 7 } & PB & ZE & ZE & PM & PB & PB \\
\hline
\end{tabular}

\section{Artificial Neural Network (ANN) Controller}

ANN is information processing system, in this system the element called as neurons process the information. The signals are transmitted by means of connecting links. The links process an associated weight, which is multiplied along with the incoming signal (net input) for any typical neural net. The output signal is obtained by applying activations to the net input. The field of neural networks covers a very broad area. Neural network architecture-the multilayer perceptron as unknown function are shown in Fig 5, which is to be approximated. Parameters of the network are adjusted so that it produces the same response as the 
unknown function, if the same input is applied to both systems. The unknown function could also represent the inverse of a system being controlled; in this case the neural network can be used to implement the controller (Hykin, 1994).

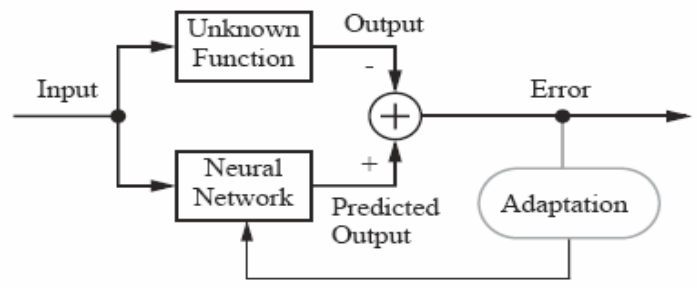

Fig. 5 Neural Network as Function Approximator

A neuron has more than one input. A neuron with inputs is shown in Fig. 6 . The individual inputs $p_{1,} p_{2, \ldots .} p_{R}$ are each weighted by corresponding elements $\mathrm{w}_{1,1}, \mathrm{w}_{1,2}, \ldots \mathrm{w}_{1, \mathrm{R}}$ of the weight matrix $W$. The neuron has a bias $b$, which is summed with the weighted inputs to form the net input $\mathrm{n}$.

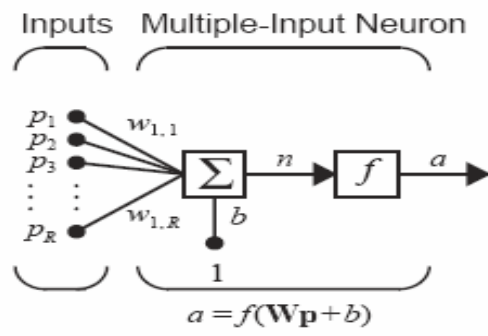

Fig. 6 Multi input neuron model

$$
n=w_{1}, p_{1}+w_{1},{ }_{2} p_{2}+\ldots \ldots \ldots+w_{1},{ }_{R} p_{R}+b
$$

This expression can be written in matrix form:

$$
n=w_{p}+b
$$

Where the matrix $w$ for the single neuron case has only one row. Now the neuron output can be written as

$$
a=f\left(w_{p}+b\right)
$$

One of the most commonly used functions is the log-sigmoid transfer function, which is shown in Figure 7.

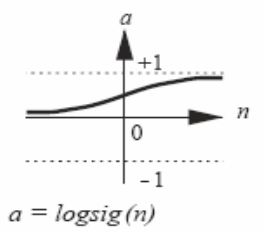

Fig.7 Log-Sigmoid Transfer Function

This transfer function takes the input (which may have any value between plus and minus infinity) and squashes the output into the range 0 to 1 , according to the expression:

$$
a=\frac{1}{1+e^{-n}}
$$

The log-sigmoid transfer function is commonly used in multilayer networks that are trained using the back propagation algorithm, in part because this function is differentiable.

4.1 NARMA-L2 Control : The ANN controller architecture employed here is a Non linear Auto Regressive Model reference Adoptive Controller. This controller requires the least computation of the three architectures. This controller is simply a rearrangement of the neural network plant model, which is trained offline, in batch form. It consists of reference, plant out put and control signal. The controller is adaptively trained to force the plant output to track a reference model output. The model network 
is used to predict the effect of controller changes on plant output, which allows the updating of controller parameters. In the study, the frequency deviations, tie-line power deviation and load perturbation of the area are chosen as the neural network controller inputs.

The outputs of the neural network are the control signals, which are applied to the governors in the area. The data required for the ANN controller training is obtained from the designing the Reference Model Neural Network and applying to the power system with step response load disturbance.

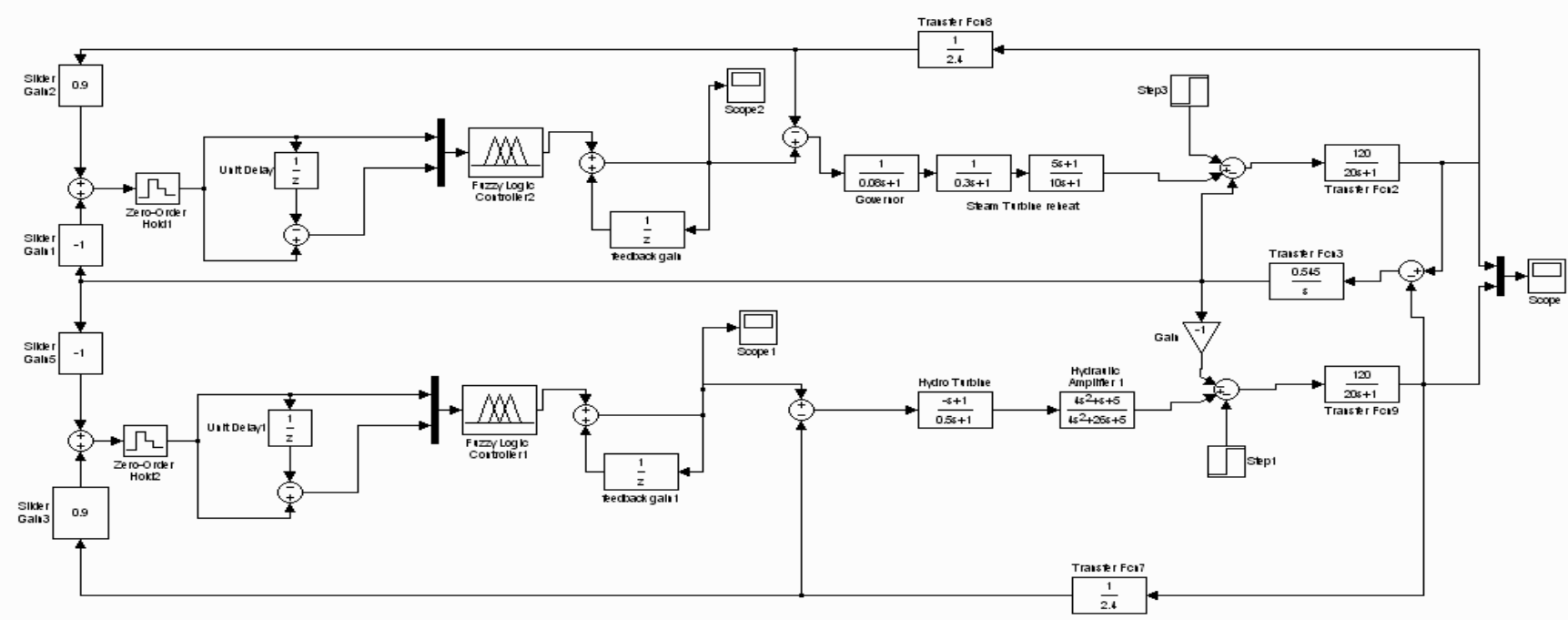

Fig. 8 Simulink Model of two area interconnected hydro-thermal reheat plant with Fuzzy controller.

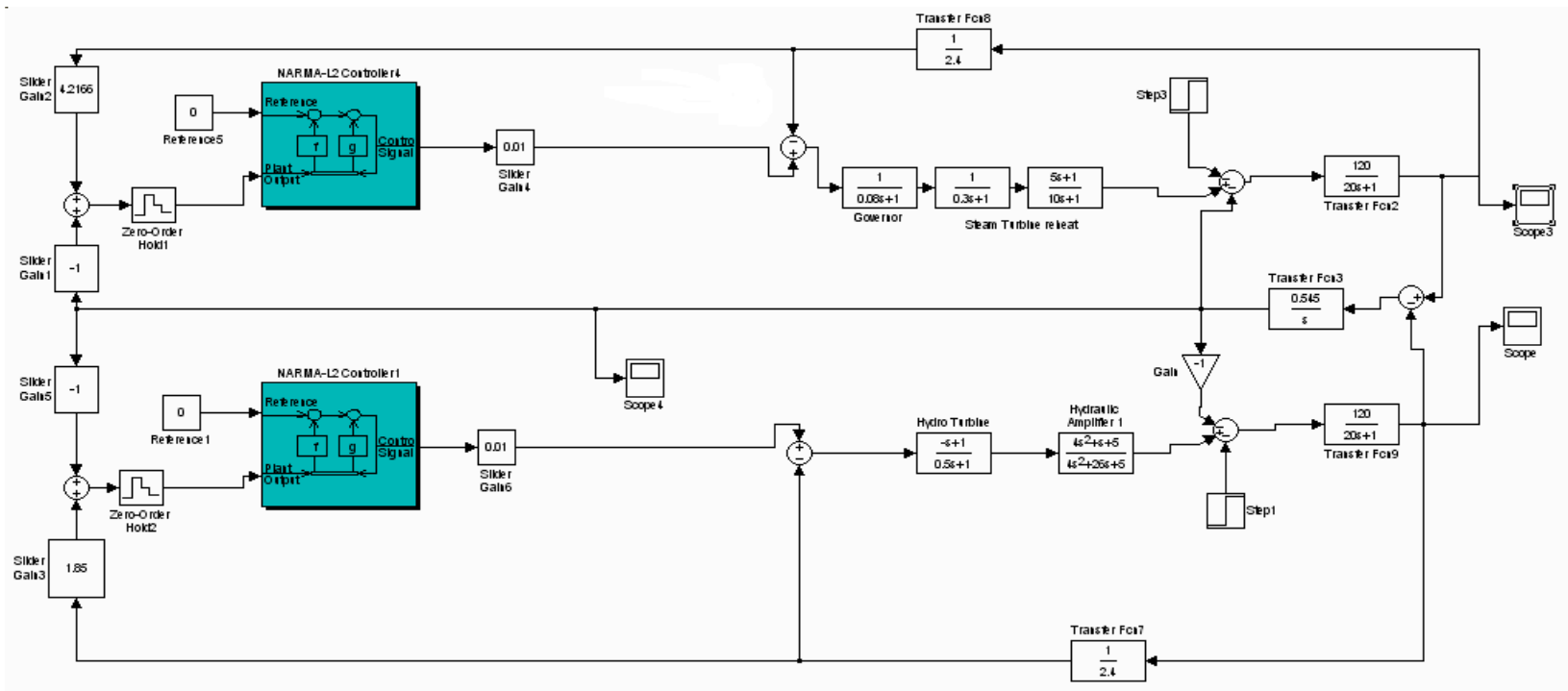

Fig. 9 Simulink Model of two area interconnected Hydro-Thermal Reheat plant with Neural Network controller 
After a series of trial and error and modifications, the ANN architecture provides the best performance. It is a three-layer perceptron with five inputs, 13 neurons in the hidden layer, and one output in the ANN controller. Also, in the ANN Plant model, it is a three-layer perceptron with four inputs, 10 neurons in the hidden layer, and one output. The activation function of the networks neurons is trainlm function.300 training sample has been taken to train 300 no of epochs. The proposed network has been trained by using the learning performance. Learning algorithms causes the adjustment of the weights so that the controlled system gives the desired response.

\section{Simulation and Result}

In this presented work, Thermal-hydro interconnected power system have been developed with fuzzy logic and ANN controllers to illustrate the performance of load frequency control using MATLAB/SIMULINK package. The parameters used for simulation are given in appendix. Two types of Simulink models are developed with fuzzy controller and ANN controller based as shown in Fig. 8 and Fig.9, respectively to obtain better dynamic behavior.

Refer to Simulink models, frequency deviation plots for thermal and hydro both cases are drawn combined and separately for $1 \%$ and $2 \%$ step load changes in system frequency and tie-line power as shown in Fig. 10-22 respectively.

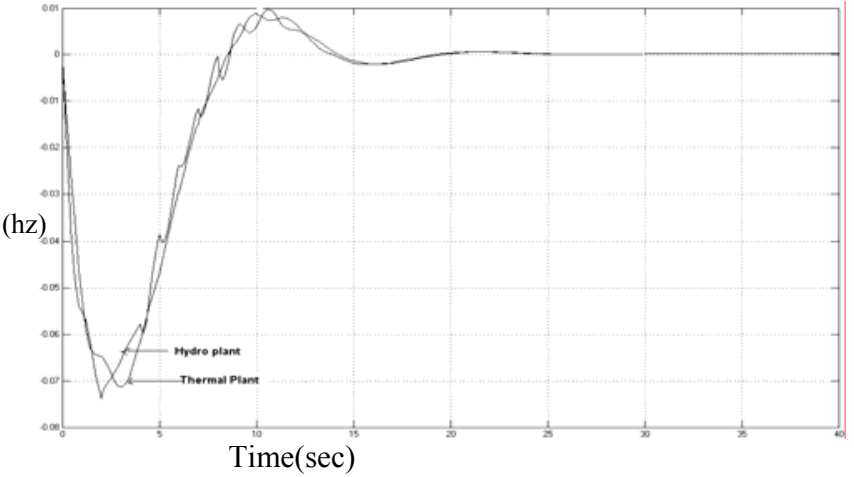

Fig.10 Combined Response of Hydro-thermal plant with fuzzy controller( $1 \%$ load variation).

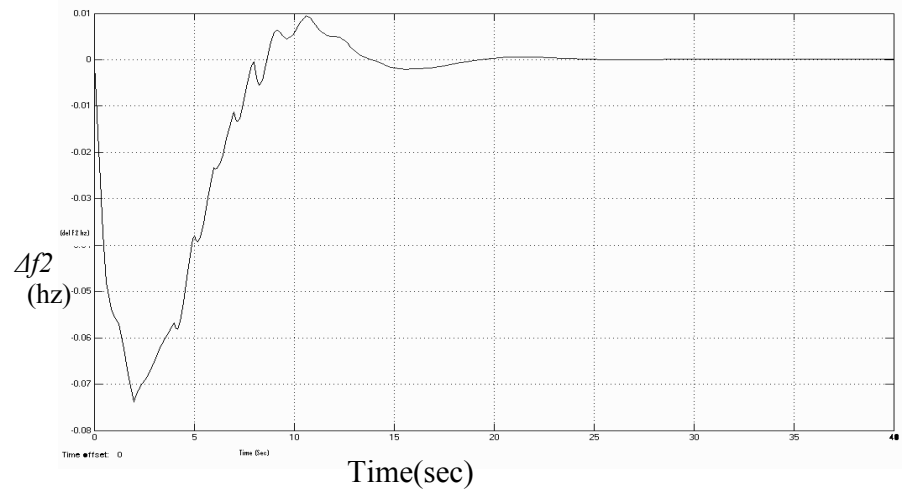

Fig. 12 Change in frequency (Hydro plant)- Fuzzy controller $\left(\Delta f_{2}\right)$ (1\% load variation.)

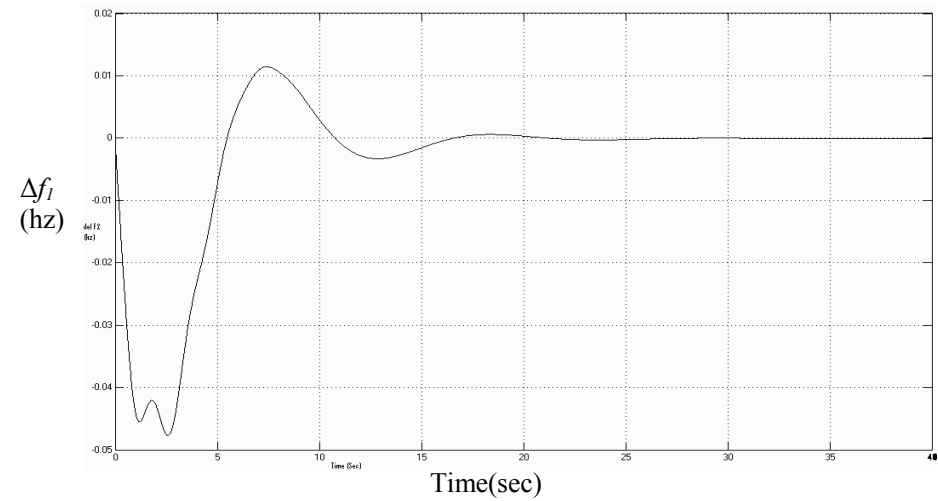

Fig. 14 Change in frequency (Thermal plant) with ANN controller $\left(\Delta f_{1}\right)$ ( $1 \%$ load variation).

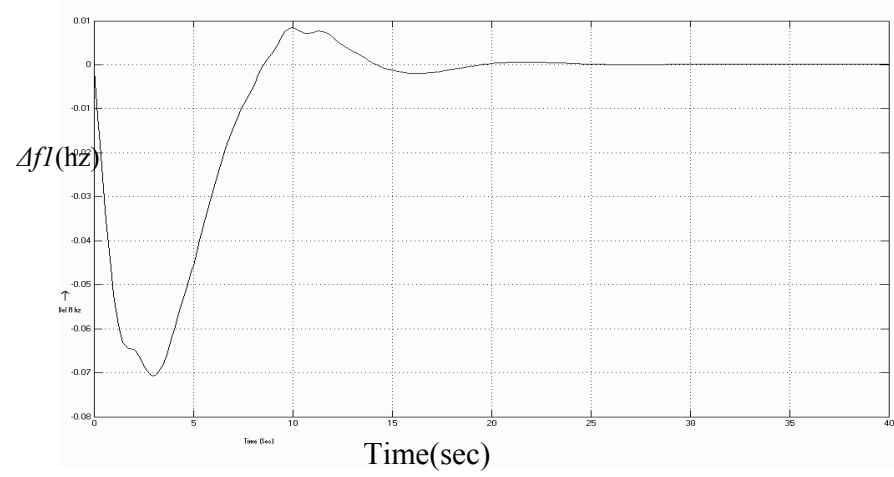

Fig. 11 Change in frequency (thermal plant) - Fuzzy with controller $\left(\Delta f_{1}\right)(1 \%$ load variation $)$.

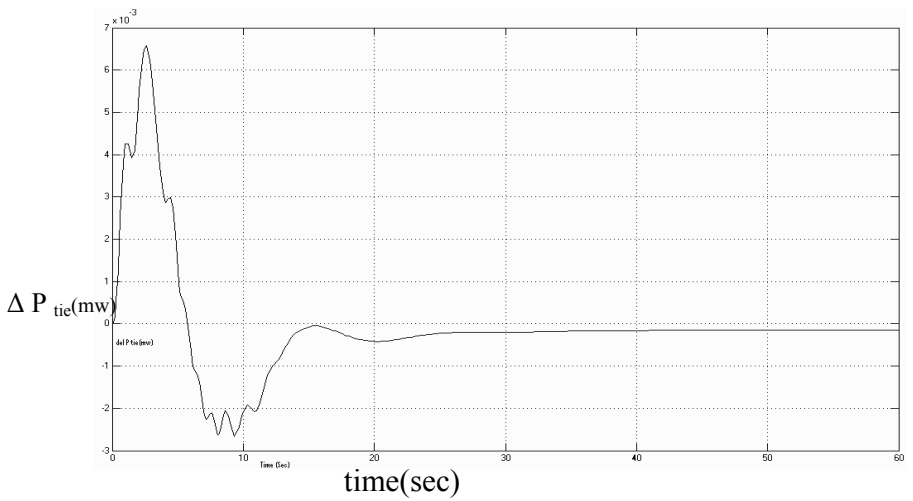

Fig. 13 Change in Tie-line power (hydro-thermal plant) with fuzzy control $\left(\Delta \mathrm{P}_{\text {tie }}\right)(1 \%$ load variation).

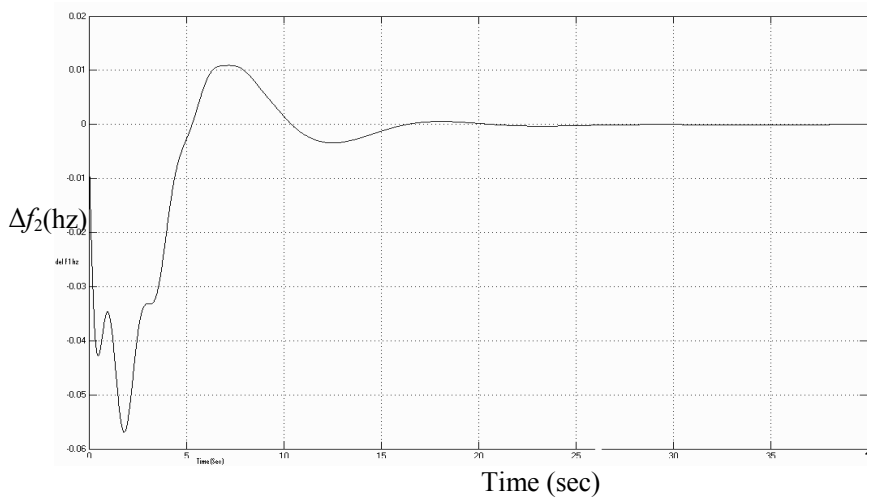

Fig.15 Change in frequency (Hydro plant) with ANN controller $\left(\Delta f_{2}\right)$ ( $1 \%$ load variation). 


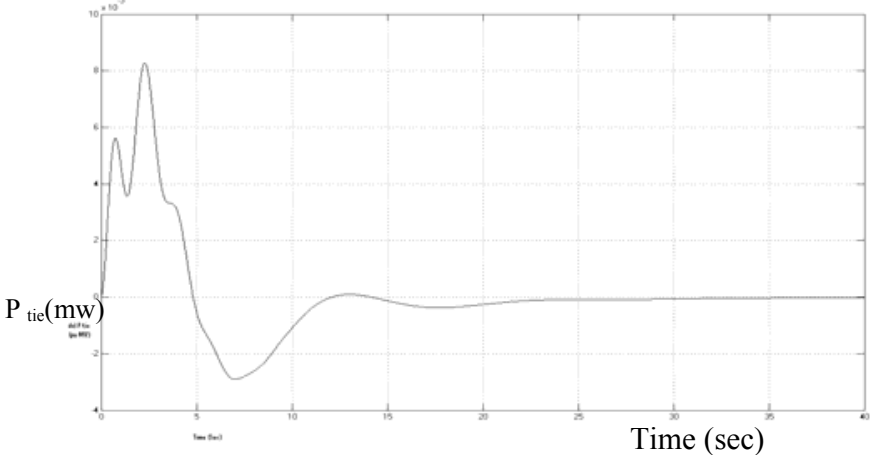

Fig. 16 Change in Tie-line power (hydro-thermal plant) with ANN controller $\left(\Delta \mathrm{P}_{\text {tie }}\right)(1 \%$ load variation).

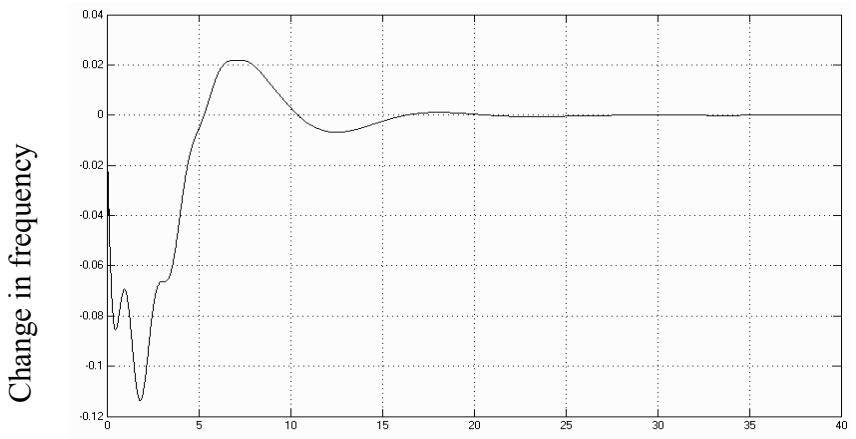

Fig. 18 Change in frequency (hydro plant) with ANN controller $\left(\Delta f_{1}\right)(2 \%$ load variation $)$.

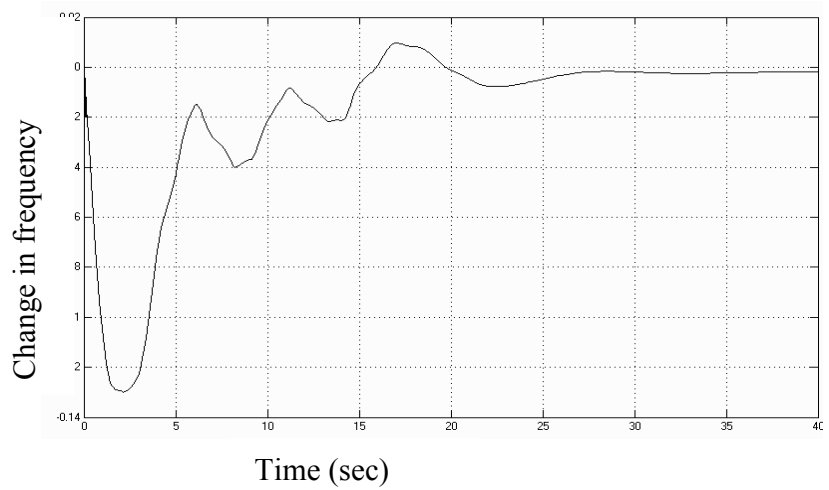

Fig. 20 Change in frequency (Thermal plant) with fuzzy controller $\left(\Delta f_{1}\right)(2 \%$ load variation $)$.

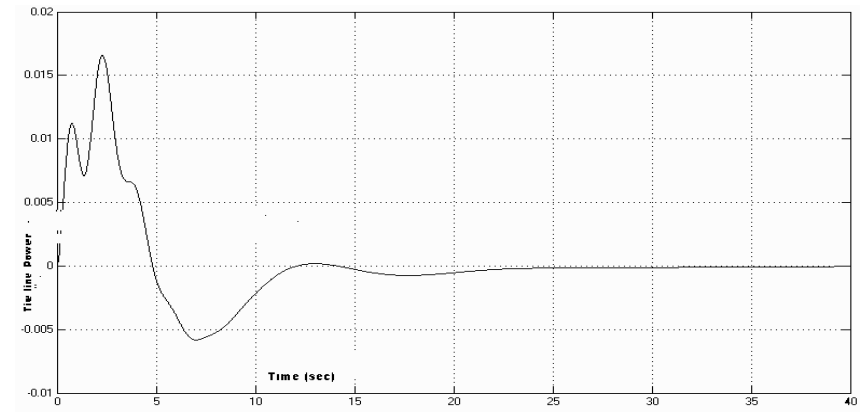

Fig. 17 Change in Tie-line power (hydro-thermal plant) With ANN controller (2\% load variation)

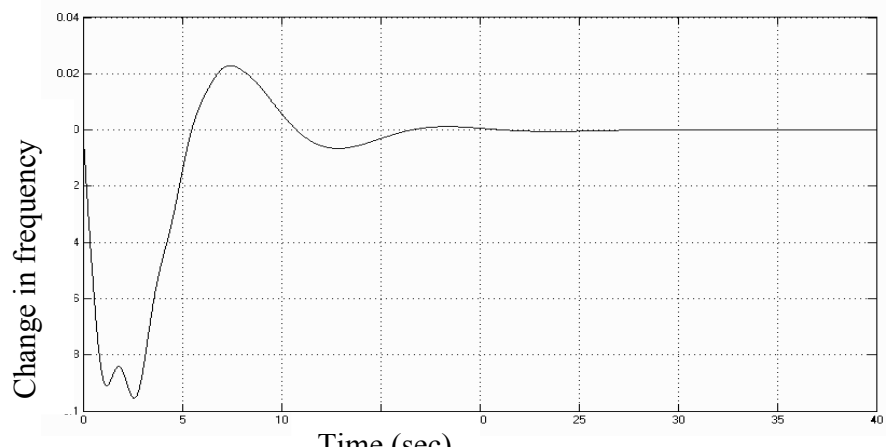

Fig.19 Change in frequency (thermal plant) with ANN controller $\left(\Delta f_{2}\right)(2 \%$ load variation $)$.

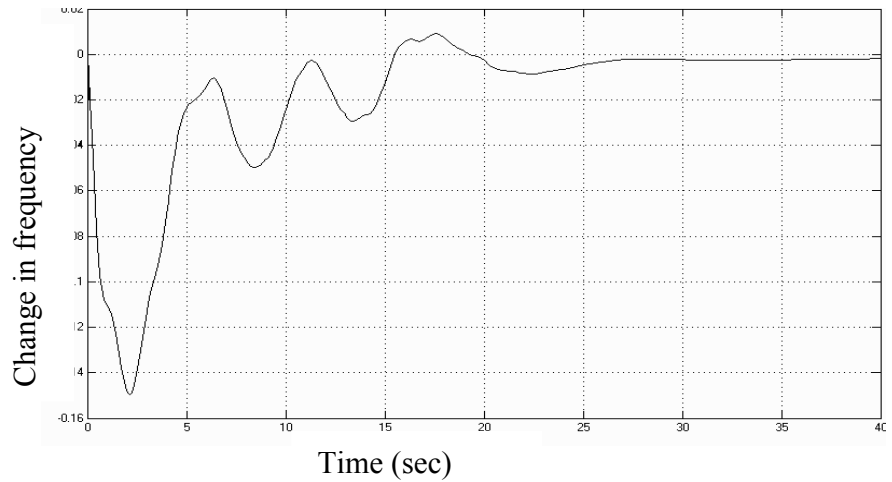

Fig.21 Change in frequency (Hydro plant) With fuzzy controller $\left(\Delta f_{2}\right)$ ( $2 \%$ load variation).

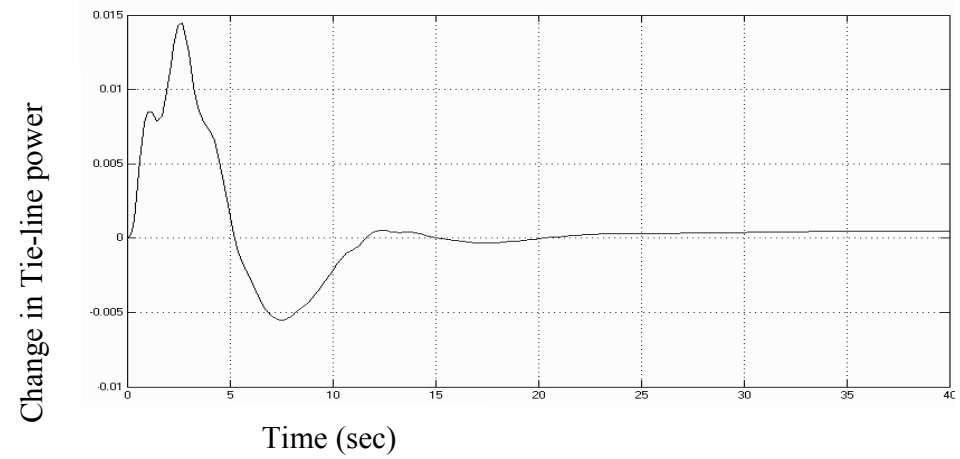

Fig. 22 Change in Tie-line power (hydo-theraml plant) with fuzzy control $\left(\Delta \mathrm{P}_{\text {tie }}\right)(2 \%$ load variation). 
With $1 \%$ and $2 \%$ step load change in both Hydro-Thermal Reheat areas with fuzzy controller and ANN controller, the steady state error is minimized to zero. Settling time and maximum peak overshoot in transient condition for both change in system frequency and change in tie-line power for different loading conditions are given in table 2-5 respectively. By this proposed method the responses obtained are better than the previous works already reported in (Gayadhar et al. 2009; Ram et al. 2010; Anand et al., 2009; Shayeghi et al. 2004).

Table: 2. Comparative study of settling time ( $1 \%$ load variation)

\begin{tabular}{|c|c|c|c|}
\hline Controllers & $\begin{array}{c}\Delta f_{1} \\
\text { Area 1 } \\
(\mathrm{sec})\end{array}$ & $\begin{array}{c}\Delta f_{2} \\
\text { Area 2 } \\
(\mathrm{sec})\end{array}$ & $\begin{array}{c}\Delta \mathrm{P}_{\text {tie }} \\
(\mathrm{sec})\end{array}$ \\
\hline Fuzzy & 23 & 23 & 27 \\
\hline ANN & 17 & 17 & 23 \\
\hline
\end{tabular}

Table: 4. Comparative study of settling time ( $2 \%$ load variation)

\begin{tabular}{|c|c|c|c|}
\hline Controllers & $\begin{array}{c}\Delta f_{1} \\
\text { Area 1 } \\
(\mathrm{sec})\end{array}$ & $\begin{array}{c}\Delta f_{2} \\
\text { Area 2 } \\
(\mathrm{sec})\end{array}$ & $\begin{array}{c}\Delta \mathrm{P}_{\text {tie }} \\
(\mathrm{sec})\end{array}$ \\
\hline Fuzzy & 28 & 28 & 25 \\
\hline ANN & 17 & 17 & 23 \\
\hline
\end{tabular}

Table: 3. Comparative study of peak overshoots ( $1 \%$ load variation)

\begin{tabular}{|c|c|c|c|}
\hline Controllers & $\begin{array}{c}\Delta f_{1} \\
\text { Area } 1 \text { in pu }\end{array}$ & $\begin{array}{c}\Delta f_{2} \\
\text { Area } 2 \text { in pu }\end{array}$ & $\begin{array}{c}\Delta \mathrm{P}_{\text {tie }} \\
\text { in pu }\end{array}$ \\
\hline Fuzzy & 0.071 & 0.075 & 0.0035 \\
\hline ANN & 0.045 & 0.055 & 0.003 \\
\hline
\end{tabular}

Table: 5. Comparative study of peak overshoots (2\% load variation)

\begin{tabular}{|c|c|c|c|}
\hline Controllers & $\begin{array}{c}\Delta f_{1} \\
\text { Area } 1 \text { in pu }\end{array}$ & $\begin{array}{c}\Delta f_{2} \\
\text { Area } 2 \text { in pu }\end{array}$ & $\begin{array}{c}\Delta \mathrm{P}_{\text {tie }} \\
\text { in pu }\end{array}$ \\
\hline Fuzzy & 0.13 & 0.15 & 0.015 \\
\hline ANN & 0.09 & 0.11 & 0.015 \\
\hline
\end{tabular}

\section{Conclusions}

With $1 \%$ load variation in power system the results shown in Tables 2 to 5 are obtained. The Intelligent control approach (Fuzzy Controller and ANN controller) with inclusion of slider gain provides better dynamic performance and reduces the oscillation of the frequency deviation and the tie line power flow in each area in hydro-thermal combination. Form the above table it is clear that responses obtained, reveals that ANN controller with sliding gain provides better settling performance than Fuzzy. By increasing the percentage deviation in load power, the ANN controller tries to maintain the settling time as previous one but peak overshoot changes slightly. In Fuzzy control approach by changing percentage load deviation the settling time is increased and peak overshoot as well. Therefore, the intelligent control approach using ANN concept is more accurate and faster than the fuzzy control scheme even for complex dynamical system at different loading conditions.

\section{References}

Anand B., Ebenezer A. Jeyakumar. 2009. Load frequency control with fuzzy logic controller considering non-linearities and boiler dynamics, ICGST-ACSE Journal, ISSN 1687-4811, Volume 8, issue 111, pp 15-20.

Aravindan P., Sanavullah M.Y. 2009. Fuzzy Logic Based Automatic Load Frequency Control of Two Area Power System With GRC, International Journal of Computational Intelligence Research, Volume 5, Number 1. pp. 37-44.

Demiroren A., Zeynelgil H.L., Sengor N. S. 2001. The Application of ANN Technique to Load-frequency Control for Three- area Power System, IEEE Porto Power Tech Conference, PPT001, $10^{\text {th }}-13^{\text {th }}$ September2001, Porto, Portugal.

Elgerd O. I. 1971. Electric Energy System Theory; An Introduction, Mc Gro Hill.

Gayadhar-Panda, Sidhartha-Panda, Cemal Ardil. 2009. Automatic Generation Control of Interconnected Power System with Generation Rate Constraints by Hybrid Neuro Fuzzy Approach, World Academy of Science, Engineering \& Technology 52, pp-543-548.

George-Gross, Lee J.W. 2001. Analysis of Load Frequency Control Performance Assessment Criteria, IEEE transaction on Power System, Vol. 16, No. 16, pp. 520-525. 
Ha Q. P. 1998. A Fuzzy sliding mode controller for Power System Load Frequency Control. Second International Conference of Knowledge based Intelligent Electronic System, 21-23 April, Vol. 1, pp. 149-154.

Hykin S. 1994. Neural Network, Mac Miller NY.

Ibraheem, Kumar P., Kothari D.P., 2005. Recent Philosophies of Automatic Generation Control strategies in Power systems, IEEE Transaction on Power System Vol.20, No.1, pp-346-357.

John Y., Hung. 1993. Variable Structure Control: A Survey, IEEE Transaction on Industrial Electronics, Vol. 40, No.1.

Kothari D. P., Nagrath I.J., 2003. Modern Power System Analysis, Tata Mc Gro Hill, Third Edition.

Kumar A., Malik O.P., Hope G. S.1985. Variable-structure- system control applied to AGC of an interconnected power System, I.E.E.E. 1EE PROCEEDINGS, Vol. 132, Pt. C, No. 1,pp. 23-29.

Kundur P, 1994. Power System Stability and Control, Mc Graw hill New York.

Magla A., Nanda J. 2004. Automatic Generation Control of an Interconnected Hydro- Thermal System Using Conventional Integral and Fuzzy logic Control, In Proc. IEEE Electric Utility Deregulation, Restructuring and Power Technologies.(DRPT2004), Hong Kong, pp. 372-377.

Masiala M., Ghnbi M., Kaddouri A. 2004. An Adaptive Fuzzy Controller Gain Scheduling for Power System Load-Frequency Control, IEEE International Conference on Industrial Technology, (ICIT).pp.1515-1520.

Mines J. N. 1997. MATLAB Supliment to Fuzzy \& Neural approach in Engineering, John Wiley NY.

Nanda J., Kakkarum J.S. 2003. Automatic Generation Control with Fuzzy logic controllers considering generation constraints, In Proceeding of $6^{\text {th }}$ Int Conf on Advances in Power System Control Operation and managements" Hong Kong.

Panna-Ram, Jha A.N. 2010. Automatic Generation control of interconnected hydro-thermal system in deregulated environment considering generation rate constraints, International Conference on Industrial Electronics, Control and Robotics, pp 148158.

Ross T.J. 1995. Fuzzy logic with engineering application. Mc Gro Hill, International Edition.

Shayeghi H., Shayanfar H.A. 2004. Power system load frequency control using RBF neural network based on $\mu$-Synthesis theory, Proceeding of IEEE conference on cybernatics and intelligent system Singapore, 1-3 Dec 2004, pp 93-98.

Shayeghi H., Shayanfar H. A., Jalili A. 2009. Load frequency control strategies: A state-of-the- art survey for the researcher, Energy Conversion and Management 50, pp 344-353, ELSEVIER.

Surya-Prakash, Sinha S.K., Brijesh-Singh, Pandey A.S. 2009. Impact of slider gain on Load Frequency Control using Fuzzy Logic Controller, ARPN Journal of Engineering and Applied Science, Vol. 4, No 7.pp. 20-27.

Talaq J., Fadel A.1., Basri, 1999. Adaptive Fuzzy gain scheduling for Load Frequency Control, IEEE Transaction on Power System, Vol. 14. No.1, pp.145-150.

Wadhawa C.L., 2007. “Electric Power System” New Age International Pub. Edition.

\section{Appendix}

Parameters are as follows:

$f=50 \mathrm{~Hz}, \mathrm{R}_{1}=\mathrm{R}_{2}=2.4 \mathrm{~Hz} /$ per unit $\mathrm{MW}, \mathrm{Tg}=0.08 \mathrm{sec}, \mathrm{Tp}=20 \mathrm{sec}$

$\mathrm{P}$ tie, $\max =200 \mathrm{MW}$

$\operatorname{Tr}=10 \mathrm{sec} \quad \mathrm{kr}=0.5$,

$\mathrm{H}_{1}=\mathrm{H}_{2}=5 \mathrm{sec} \quad \mathrm{P}_{\mathrm{r} 1}=\mathrm{P}_{\mathrm{r} 2}=2000 \mathrm{MW}$

$\mathrm{Tt}=0.3 \mathrm{sec} \quad \mathrm{Kp}_{1}=\mathrm{Kp}_{2}=120 \mathrm{~Hz} \cdot \mathrm{p} . \mathrm{u} / \mathrm{MW}$

$\mathrm{Kd}=4.0 \quad \mathrm{ki}=5.0 \quad \mathrm{Tw}=1.0 \mathrm{sec}$

$\mathrm{D}_{1}=\mathrm{D}_{2}=8.33 * 10^{-3}$ p.u MW/Hz.

\section{Nomenclature}

$F \quad: \quad$ Nominal system frequency

$P_{\mathrm{ri}} \quad: \quad$ Area rated power, $H_{\mathrm{i}}$ : Inertia constant

$\triangle P_{D i} \quad: \quad$ Incremental load change

$\Delta P g \quad i \quad: \quad$ Incremental generation change

$D i \quad=\frac{\Delta \quad \mathrm{P} \text { Di }}{\Delta \text { fi }}$

$T_{12}$ : $\quad$ Synchronizing coefficient, $T_{\mathrm{g}}$ :Steam governor time constant

$K_{r}: \quad$ Reheat constant, $T_{\mathrm{r}}$ : Reheat time constant

$T_{t}: \quad$ Steam turbine time constant

$R_{i}$ : $\quad$ Governor speed regulation parameter

$B_{i}$ : $\quad$ Frequency bias constant

$T_{\mathrm{pi}}: \quad 2 \mathrm{Hi} / \mathrm{f} * \mathrm{Di}, K_{\mathrm{pi}}: 1 / \mathrm{Di}$

$K_{\mathrm{j}}: \quad$ Integral gain

$K_{d}, K_{p}, K_{i}$ : Electric governor derivative, proportional and 


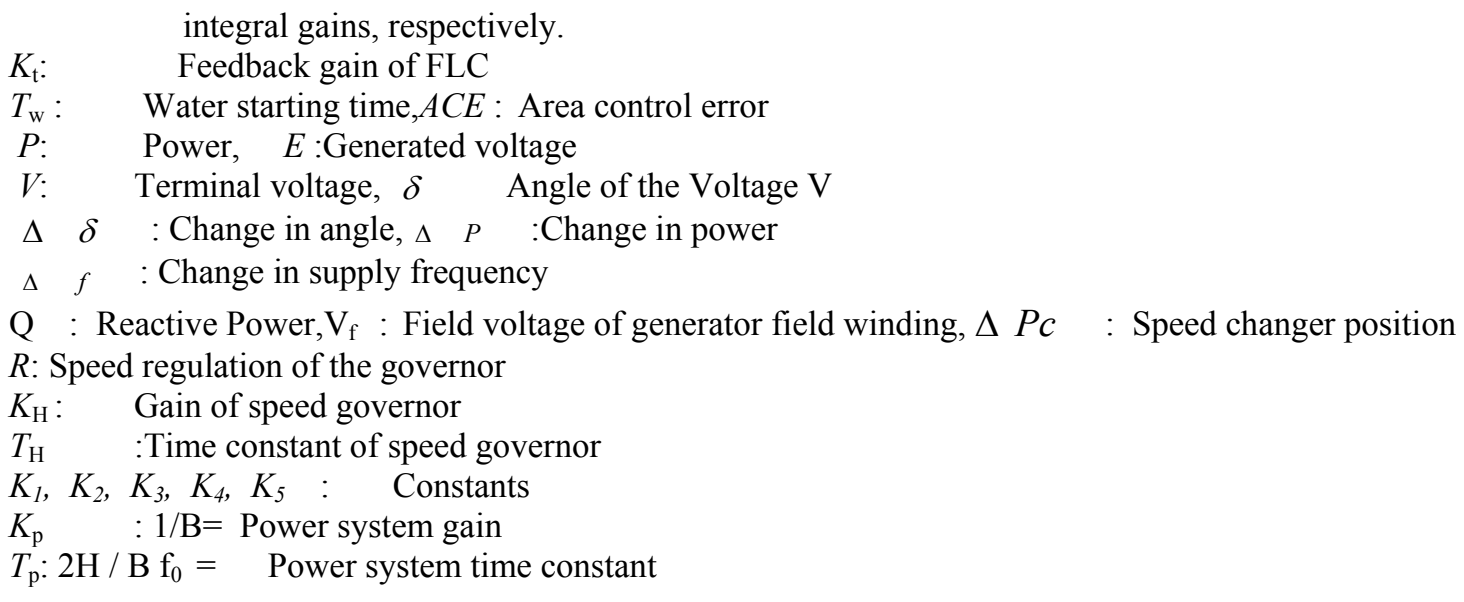

\section{Biographical notes}

Surya Prakash Allahabad, 01.05.1971, Received his Bachelor of Engineering degree from The Institution of Engineers(India) in 2003, He obtained his M.Tech. in Electrical Engg.(Power System) from KNIT, Sultanpur.UP-India in 2009. Presently he is Pursuing Ph. D in Electrical Engg. Load Frequency Control and working as Assistant Professor in SSET, SHIATS(Formerly Allahabad Agriculture Institute, Allahabad- India) . He is associate Member of The Istitution of Engineeris (India), e-mail: sprakashgiri0571@yahoo.com MB 09956722055

Dr. S. K. Sinha belongs to Varanasi and his date of birth is $17^{\text {th }}$ Apr 1962. He received the B.Sc. Engg degree in Electrical from R.I.T. Jamshedpur, Jharkhand, India, in 1984, the M. Tech. degree in Electrical Engineering from Institute of Technology, B.H.U, Varanasi, India in 1987, and the Ph.D. degree from IIT, Roorkee, India, in 1997. Currently he is working as Professor \& Head, Department of Electrical Engineering, Kamla Nehru Institute of Technology, Sultanpur, UP, India . His fields of interest includes estimation, fuzzy control, robotics, and AI applications. e-mail: sinhask98@engineer.com

Received November 2010

Accepted June 2011

Final acceptance in revised form July 2011 